\title{
SEXO É SÓ PARA QUEM PODE PAGAR: UM DIÁLOGO COM O COTIDIANO DA PROSTITUIÇÃO NO PARÁ
}

\section{RESUMO}

Augusto César Pinto Figueiredo ${ }^{1}$

O presente artigo é o resultado do primeiro ano de pesquisa de campo desenvolvida para a tese de doutorado intitulada: "A história da prostituição em áreas de barragens na Amazônia: O lado sombrio do grande capital", e das discussões gestas na disciplina "Sociobiodiversidade e trabalho". No presente artigo abordamos diversos aspectos como perfil das profissionais do sexo, perfil dos clientes, valor dos programas, abordamos brevemente os motivos que levam essas pessoas a ingressarem no mercado do sexo. Falaremos sobre metodologia de pesquisa de campo, os desafios de fazer pesquisa de campo durante o período de pandemia, apresentamos a transcrição de diálogos que foram coletados ao longo do ano de 2020 com cerca de 50 profissionais do sexo. As perguntas inicialmente eram abertas, mas tão logo as entrevistadas se sentiam à vontade, as perguntas abertas davam espaço a narrativas de vida e trajetórias que iam do histórico familiar até o momento que as levou a "escolha" do mercado da prestação de serviços sexuais. Os dados coletados resultaram numa tabela que apresentamos as características físicas, faixa etária, os tipos de programas e os cachês médios cobrados por programa.

Palavras-chave: Prostituição. Profissionais do sexo. História oral. Serviços sexuais.

\section{SEX IS RESERVED FOR THOSE WHO CAN AFFORD IT: A DIALOGUE WITH THE DAILY PROSTITUTION IN PARÁ}

\begin{abstract}
This article is the result of the first year of field research developed for the doctoral thesis entitled: "The history of prostitution in dam areas in the Amazon: The dark side of great capital", It is also the results of the discussions conducted in the discipline "Sociobiodiversity and job". This paper, we discuss several aspects such as the profile of sex workers, the profile of clients, the value of a pool, we briefly discuss the reasons that lead these people to enter the sex market. We talk about the challenges of doing field research during the pandemic period, we present the transcript of dialogues that were collected throughout the year 2020 with a total of 50 sex workers. The questions were initially open, but as soon as the interviewees felt at ease, the open questions turned into life narratives and trajectories that started from family history to the moment that led them to "choose" the sex market. The data collected resulted in a table that presents the physical characteristics, age group, types of pooling and the average fees charged per pooling.
\end{abstract}

Keywords: Prostitution. Sex workers. Oral history. Sexual pooling.

Data de submissão: 19. 04. 2021

Data de aprovação: 15.05 .2021

\section{INTRODUÇÃO}

Segundo dados de 2015, da Fundação Mineira de Educação e Cultura, FUMEC, estima-se que o Brasil possui 1,5 milhões de pessoas, entre homens e mulheres, que vivem em situação de prostituição. No entanto, o que leva uma mulher a entrar no mercado da prestação de serviços sexuais? A prostituição pode ser considerada uma profissão? Quem as apresenta a esse mercado? Quais os critérios que tornam a prestação de serviços sexuais um mercado lucrativo para algumas mulheres e pouco rentável para outras? Quanto ganha,

\footnotetext{
${ }^{1}$ Professor efetivo da Universidade Federal do Pará. Doutorando do Programa de Pós-Graduação em História da Amazônia da Universidade Federal do Pará. E-mail: figueiredoacp@ hotmail.com.
} 
aproximadamente, uma operária do sexo? Qual o perfil dos homens que buscam esse tipo de companhia?

Guimarães Neto (2014, p. 28) explica que historiadores e estudiosos das ciências sociais investigam, primordialmente, os momentos e contextos políticos, econômicos e culturais em que as diversas práticas de trabalho emergem e se tornam corrente no dia a dia das sociedades. O comércio de prestação de serviços sexuais é indubitavelmente uma prática de trabalho que se fez e faz muito presente no cotidiano de nossa sociedade.

Outro fator deveras relevante é a questão psicológica que muitas vezes passa despercebida no universo da prestação de serviços sexuais. Muitos relatos colhidos no presente trabalho expressam fortemente questões como: abusos na infância, iniciação sexual precoce, insegurança com o corpo e bullying sofrido ao longo da infância e adolescência. Thompson (2002, p. 12) explica que:

\footnotetext{
Muitas vezes surpreendo-me pela resistência, particularmente dos sociólogos, a essa dimensão psicológica. Muito recentemente, estive discutindo com uma amiga brasileira sua pesquisa sobre o turismo sexual. Elementos cruciais na situação são obviamente a desigualdade econômica, a pobreza das mulheres brasileiras locais e a riqueza dos turistas visitantes, e as imagens quase contrárias que têm um do outro: os turistas imaginando as mulheres brasileiras como altamente sexuais, "tropicais", enquanto as mulheres achando que os homens são frios e pouco exigentes sexualmente. Mas enquanto essas pressões estruturais compõem o contexto para o turismo sexual, elas não explicam porque certas mulheres se tornam prostitutas e outras não. Poderíamos supor que outros fatores psicológicos estejam envolvidos, tais como o aban- dono na infância, uma mãe distante e fria ou o abuso sexual por parte do pai ou avô. Creio que tanto as perspectivas sociais quanto as psico- lógicas são igualmente relevantes para a interpretação (THOMPSON, 2002, p. 12).
}

Ao refletirmos sobre as perguntas que guiaram o presente trabalho surgiu outro questionamento. Qual aporte metodológico seria o ideal para trabalharmos com narrativas orais dessas operarias do sexo? A resposta foi quase que imediata, optamos pelo uso da História Oral. Thompson (2000, p.10) explica que, em primeiro lugar, a história oral é um método que sempre foi essencialmente interdisciplinar, um caminho cruzado entre sociólogos, antropólogos, historiadores, estudantes de literatura e cultura, dentre outros. Thompson continua relatando que, ao longo de sua vida de pesquisador, ele sempre observou como determinadas disciplinas podem ser transformadas por novos modos de pesquisa, além de ver como uma força crucial da história e o fato dela permanecer como uma forma fundamental de interação humana, que transcende as fronteiras disciplinares.

\section{FUNDAMENTAÇÃO TEÓRICA}

Alberti (2005, p.155-202) enfatiza alguns equívocos sobre a História oral que devem ser descartados de imediato, como a consideração de que a História oral é a própria História; de que a história vista "de baixo" é a democrática, em oposição à história das elites; e que a História oral busca dar voz às minorias, o que apenas reforçaria as diferenças sociais. Para a autora, a História oral deve ser compreendida como visões de mundo e experiências de vida. Logo, dar voz aos relatos de vida de mulheres que estão à margem da sociedade, por meio de seus relatos de vida, é comprimir com o papel não só de historiador, mas de partícipe de um grupo de pessoas que buscam, por meio das ciências sociais, derrubar barreiras e, talvez, assim, minimizar ao máximo as mazelas sociais que as meretrizes historicamente são submetidas.

Utilizar a História oral é trabalhar num campo movediço, onde questões, como a veracidade dos depoimentos, devem ser consideradas como elemento válido dentro de uma pesquisa acadêmica séria. Ou mesmo, por se tratar de uma questão mais voltada à memória individual, não deva ser considerado como apenas um imaginário das entrevistadas, uma 
tentativa de maquiar uma realidade dura e cruel no cotidiano que muitas vezes, é transformar em um "conto de fadas, ou até mesmo o oposto".

Neste caso, David (2013, p. 160) explica que a problemática da verdade não deve subjugar o trabalho com a História oral. Sem questionar a busca contínua pelo como se deu determinado fato ou evento histórico, mas devemos reconhecer a multiplicidade de narrativas, buscar compreender que o depoimento oral é desencadeado pela construção de uma narrativa ucrônica $^{2}$ (PORTELLI, 1993, p. 41-58), inserida no campo da memória e que determina aquilo que o personagem gostaria que tivesse ocorrido ou a sua representação do real.

David (2013, p. 160) complementa afirmando que não se trata de questionar a verdade ou não do depoimento, mas apenas compreender que esse é construído socialmente pelo entrevistado que, dando sentido à sua vida, arquiteta um ponto de vista, uma representação sobre determinado momento relacionado à sua trajetória. E mesmo que essas lembranças possam indicar a representação do indivíduo sobre determinado fato ou evento, elas estão carregadas de densidade histórica e demonstram as múltiplas visões do passado, um ponto de vista do indivíduo que demonstra muito de si e do grupo ao qual ele pertencia.

Para muito além disso, a História oral nos subsidia com elementos para melhor compreender a possibilidade de múltiplas narrativas e que essas apontam que não há uma verdade única e que, em decorrência da sociedade ser composta por diversos grupos sociais participantes concomitantemente de um mesmo período ou evento histórico, cada grupo terá uma visão de mundo, uma experiência de vida que compõe o todo. (DAVID 2013, p.160) Thompson (2002, p. 16) deixa bem claro a importância do uso da História oral, uma vez que todo homem e toda mulher têm uma história de vida para contar que é de interesse histórico e social, e muito se pode compreender a partir dos poderosos e privilegiados, tais como proprietários de terra, advogados, padres, empresários, banqueiros, etc.

Entretanto, a História oral tem um poder único de nos dar acesso às experiências daqueles que vivem às margens do poder, e cujas vozes estão ocultas, pois as vidas dessas pessoas são praticamente improváveis de serem documentadas nos arquivos. Thompson enfatiza ainda que essas vozes ocultas são acima de tudo de mulheres, e é justamente por isso que a História oral tem sido tão fundamental para a criação da História das mulheres.

No entanto, ao trabalhar com História oral é necessário, na hora da entrevista, o pesquisador ter amplo conhecimento do assunto, pois este será constantemente sabatinado por seus entrevistados. Um dos maiores entreves na hora de entrevistar é não estar devidamente munido de informações básicas e demonstrar para o seu entrevistado o desconhecimento de suas práticas e terminologias locais.

Quando o entrevistado reconhece que o pesquisador tem clareza ao tratar do métier do entrevistado, o pesquisador conquistará confiança e respeito tendo a oportunidade de obter ainda mais informações e detalhes, que são imprescindíveis para a sua pesquisa. Thompson (1992, p. 255) explica que:

\begin{abstract}
A menos que o informante seja, de algum modo, mais bem informado do que o entrevistador. Este vem para aprender e, de fato, muitas vezes consegue que as pessoas falem exatamente dentro desse espírito. Por exemplo, Roy Hay descobriu, em sua pesquisa com construtores navais que Clydeside, que, muitas vezes, 'nossa própria ignorância' pode tornar-se útil. Em muitas ocasiões, são trabalhadores mais velhos recebiam minhas perguntas ingênuas com divertida tolerância e me diziam 'Não, não, garoto, não foi desse jeito', ao que se seguia uma descrição clara e detalhada do que verdadeiramente acontecera" (THOMPSON, 1992, p. 255).
\end{abstract}

\footnotetext{
${ }^{2}$ Neste texto, o autor destaca que as narrativas se apresentam como sonhos de uma vida que poderia ter ocorrido de maneira diversa, não se encontra na realidade, mas, sim, na possibilidade desejada, e a função do ucrônico seria a de sustentar a esperança.
} 
Escolhemos fazer entrevistas e utilizar questionários tanto abertos quanto fechados. As entrevistas foram feitas ao longo do ano de 2020, nas cidades de Belém, Ananindeua, Marituba, Tucuruí, Altamira e Santarém no estado do Pará. Ademais, utilizamos as entrevistas tanto para coleta de dados quantitativos quanto quanlitativos, bem como dar voz a essas mulheres que raramente têm os seus relatos de vida documentados. Thompson (2002, p. 16) reforça que o ponto chave é que os historiadores orais deveriam sempre pensar sobre as implicações quantitativas de sua pesquisa, e ter uma estratégia de amostragem que se adapte a seus propósitos, e, assim, visar a um poder explanatório que é ao mesmo tempo qualitativo e quantitativo.

Bruns e Gomes (1996), durante pesquisa de campo, procuraram compreender a prática da prostituição a partir de como essas profissionais do sexo vivenciavam sua sexualidade. Para isso, os autores realizaram entrevistas com 15 prostitutas institucionalizadas, com idade entre 18 e 33 anos, com escolaridade até o ensino médio.

Inicialmente foram trabalhadas perguntas fechadas, logo depois abertas e, por fim, assim que as entrevistadas se sentiam à vontade, as perguntas abertas davam espaço às narrativas de vida e trajetórias que iam do histórico familiar até o momento que as levou a "escolha" do mercado da prestação de serviços sexuais como alternativa de trabalho. Seja qual for o motivo, e aqui usaremos uma frase um tanto clichê, mas o mercado do sexo pago só existe porque existe demanda.

Para Bruns (2001), "Se existe quem vende prazer, é porque existe quem compra prazer. Essa demanda desconhece crises econômicas, pandemias, guerras e tragédias climáticas. Justamente por isso, não podemos deixar de falar mesmo que brevemente da questão da Covid 19, uma vez que nossa pesquisa foi realizada no ano de 2020, em pleno auge da pandemia.

As entrevistas foram realizadas em sua maioria por meio de vídeo chamadas, algumas por telefone, outras via chat de aplicativo de mensagens instantâneas e apenas cerca de $20 \%$ foram desenvolvidas pessoalmente. Thompson (2002, p. 26) traz à tona os desafios para os pesquisadores que utilizam a História oral como aporte metodológico. Thompson faz a seguinte indagação a respeito do uso das novas tecnologias da comunicação durante a pesquisa de campo:

Aqui já encontramos nosso quarto desafio: as novas tecnologias de comunicação.
Devemos abraçá-las como uma oportunidade maravilhosa, ou devemos reconhecê-las
como os mensageiros de nosso futuro es- quecimento? Afinal, a história oral como a
conhecemos era indubita- velmente uma criança da idade de ouro do som, quando o
rádio era a principal forma da comunicação de massa - uma era passada já distan- te.
E eu não penso que, até o momento, historiadores orais têm apre- sentado um registro
muito expressivo de afinidades com os avanços técnicos. Muitos vídeos de história
oral que foram produzidos são te- diosamente formais e repetitivos para se ver, por
que seus criadores não reconhecem a necessidade de técnicas bastante diferentes a fim
de fazer com que o trabalho audiovisual prenda os que o assistem e trans- mita sua
mensagem. E, lamentavelmente, a mesma fraqueza tem se re- petido na maior parte
dos CD-Roms de projetos de história oral que tenho visto.Existem também novas
excitantes possibilidades para difundir a história oral através da multimídia e da
internet. Dispositivos de multimídia têm um potencial especial para integrar som,
imagens visuais e texto, e eles podem ser um importante caminho de atração para uma
audiência mais jovem. Criar sites de memória na internet, e combinar di- ferentes
tipos de documento, são novas formas igualmente importantes (THOMPSON, 2002,
p. 26).

David (2013, p. 164) alerta que quando o pesquisador invade a privacidade do entrevistado, com questões que o obrigam a relembrar momentos de sua vida, muitos deles que se deseja esquecer, é muito recomendável que, seja criado um ambiente confortável para o 
entrevistado, para que o mesmo se sinta à vontade para falar ou até mesmo deixar de falar. Assim, o ambiente deve ser escolhido ou aprovado pelo próprio entrevistado. Além disso, locais relacionados ao período narrado ou à temática possibilitam a melhor rememoração do passado, sendo ainda possível a utilização de fotos ou objetos que ajudem o entrevistado a se recordar do tema proposto.

Saraiva (2009, p. 8-15) descreve em seu capítulo introdutório as dificuldades que teve para fazer a coleta de dados em ambiente de meretrício. Este capítulo serviu como norte para as minhas idas à campo. Cerca de $30 \%$ dos encontros presenciais foram realizados em quartos de Hotéis/Motéis, apartamentos alugados por temporada, locais usualmente utilizados para o atendimento de clientes, além destas, algumas poucas entrevistas foram realizadas nas próprias casas das profissionais, que também eram utilizadas como espaço de trabalho. Ressaltamos que máscaras, distanciamento social e álcool em gel foram medidas de prevenção e segurança adotadas durante as entrevistas presenciais.

Fazer a entrevista no local de atendimento dessas mulheres, teve como intuito dar subsídios para que elas pudessem acessar as camadas mais profundas de suas memórias. Quando o pesquisador opta pela coleta de depoimento oral, ele precisa ter clareza que vai adentrar em um campo delicado e íntimo da memória do entrevistado.

Saraiva (2009, p. 9) relata uma situação recorrente durante sua pesquisa de campo: mesmo depois de os pesquisadores exporem os seus objetivos às trabalhadoras do sexo, muitas delas acreditavam que pelo pesquisador ser homem ele ainda era um cliente em potencial.

Ser tratado como uma cliente em potencial, foi também uma experiência vivenciada por mim em meu trabalho, mas tal situações foram sutilmente contornadas. Em muitos momentos da pesquisa de campus, assim como Saraiva, tive de ouvir propostas que iam desde pagar para fazer sexo e poder ouvir os relatos a simplesmente pagar para ouvir somente os relatos.

As garotas de programa relataram que, por conta da pandemia, houve uma drástica redução no número de programas realizados diariamente. Alguns relatos de diminuição falam de uma perda entre $40 \%$ e $55 \%$ da renda diária obtida com os programas. Algumas meretrizes relataram que faziam entre 03 e 05 programas diários, antes da pandemia de Covid 19.

Algumas mulheres, encontraram formas alternativas de recuperarem parte dos ganhos, e ao mesmo tempo diminuir o contato social com inúmeros parceiros. Uma alternativa um tanto inusitada foi por meio de rifas. Toda a semana, um programa "completo" com uma trabalhadora do sexo era rifado. Com o valor recebido das rifas, a mulher ganhava o suficiente para o seu sustento por uma semana de trabalho, e o cliente que comprava a rifa por cerca de 15 ou 20 reais, dependendo da meretriz, ganhava um programa por um custo bastante inferior ao que pagaria usualmente num programa regular com a profissional do sexo.

Outra queixa corriqueiramente ouvida, durante as entrevistas, por parte das profissionais do sexo é que os programas são exaustivos, uma vez que os clientes demandavam delas um grande esforço físico durante o ato sexual. Os clientes pagam e querem a melhor performance possível, não levando em consideração se aquele é o terceiro ou mesmo o quinto programa do dia daquela meretriz, mas com a pandemia as coisas mudaram e ficaram mais amenas pelo número reduzido de programas.

Sob a ótica das profissionais do sexo, uma questão curiosa foi levantada por quase todas elas, durante as entrevistas, ao que concerne a diminuição do número de programas realizados. Para elas, o fato da diminuição do número de programas não ocorreu por conta do vírus, ou pela proibição de circulação das pessoas, mas pelo simples fato delas atenderem um público, majoritariamente, de mulheres e homens casados. Esses clientes teriam se sentido obrigados a ficarem confinados em casa com seus cônjuges, durante o período de quarentena, tornando a possibilidade de encontros extraconjugais praticamente inviáveis.

Muitas meretrizes também afirmam que, para elas, o motivo para o aumento da violência doméstica, e o número considerável de casais que entraram com o processo de divórcio era 
justamente por conta da rotina "aprisionada" dos cônjuges, já que esses estavam acostumados a sair 01 ou 02 vezes por semana com outras mulheres. Vale ressaltar que essas conclusões foram retiradas dos relatos das profissionais entrevistadas e, portanto, não devem ser entendidas, nesse artigo, como conclusões científicas.

Contudo, se por um lado houve uma diminuição na quantidade de programas realizados pelas profissionais do sexo, por outro, um auxílio, no valor de $\mathrm{R} \$ 600$, do Governo Federal acabou mitigando as perdas financeiras, uma vez que praticamente todas receberam o auxílio emergencial. Para muitas, esse valor não foi suficiente face ao valor perdido no número de programas, uma vez que o valor médio de um programa gira em torno de $\mathrm{R} \$ 100$ e $\mathrm{R} \$ 200$. Obviamente, estamos tratando, aqui, de média de valores. Temos clareza que dependendo das habilidades e dotes da mulher, do público alvo, do fator étnico e da idade, os cachês podem chegar próximo de $\mathrm{R} \$ 800$, ou, até mesmo $\mathrm{R} \$ 2.000$, fazendo com que algumas tenham sentido, financeiramente, mais que outras.

Durante o período de entrevistas, foi possível ter contato direto com 50 mulheres que trabalham diretamente com a prostituição. Essas mulheres têm entre 18 a 40 anos, mas por questões de sigilo e segurança, as identidades dessas mulheres serão preservadas. Como pseudônimos, ao narrarmos suas trajetórias de vida utilizaremos nomes de flores.

No momento em que as profissionais aceitavam participar da entrevista, elas eram apresentadas às flores disponíveis, essas seriam as representações de suas identidades. As flores já escolhidas eram automaticamente retiradas da lista. Dentre essas 50 mulheres, foram escolhidas 05, que aqui terão suas narrativas trabalhadas por dois motivos deveras relevantes: essas possuem mesma faixa etária, classe social e características étnicas e o fato delas não estarem satisfeitas com suas aparências físicas.

\section{DESENVOLVIMENTO}

Todavia, vamos discutir a questão da prostituição como profissão? Guimarães Neto (2014, p. 28) explica que, levando em consideração o ponto de vista historiográfico, esse campo de investigação apresenta profícuas atualizações temáticas e acaba por problematizar a historicidade das categorias trabalho e trabalhador sob diversos ângulos. Ao falarmos de prostituição, mais especificamente no contexto Amazônico, precisamos levar em consideração que a prostituição, apesar de ter entrado na classificação brasileira de ocupações (CBO) em 2002, indexada na CBO com o número 5198-05, ter reconhecido a ocupação de "profissional do sexo" como membro da família "prestador de serviço", poucas mudanças sociais efetivas foram notadas. Para Rodrigues (2003, p. 68) os êxitos dessa inclusão são insuficientes para modificar o estatuto formal da prostituição ou seu reconhecimento como profissão, isso porque o êxito inerente ao reconhecimento da profissão demandaria outras medidas relacionadas a iniciativa de legislação.

Para Rodrigues (2009), o reconhecimento da profissão, as iniciativas e legislação voltadas a esse membro da família de prestadores de serviços é uma questão crucial para o combate à sua exclusão e discriminação, bem como para a conquista da cidadania. As mudanças históricas relacionadas à liberação sexual, costumes, domínio do próprio corpo e independência foram significativas, mas não suficientes para dar às profissionais do sexo a dignidade humana inerente a todos garantida pela $\mathrm{CF} / 88$. Reduzidas a prestadoras de serviços, por enquanto, no mundo real, os avanços sobre a ocupação, trabalho, legislação e reconhecimento da prostituição foram ínfimos diante da projeção negativa em que essas profissionais hoje em dia se encontram.

Será que transformar a prostituição em serviço é uma forma de oportunizar as variações da dinâmica desse ofício de forma tão constante? 
A inclusão na CBO permite que essas mulheres venham a recolher contribuições previdenciárias, como profissional do sexo, tendo a garantia dos direitos comuns a todos os trabalhadores, como aposentadorias e auxílio doença (DONEL, 2011). A Consolidação das Leis do Trabalho - CLT não abarca esta atividade, dentre as diferentes categorias de trabalhadores, cabe a profissional de sexo recolher o valor de $20 \%$ para a previdência social sobre a renda. Por outro lado, sem declarar a profissão de meretriz, pode-se recolher $11 \%$ sobre arenda, o que garante praticamente todos os direitos previdenciários, exceção à aposentadoria por tempo de serviço e auxílio doença por moléstia que não permita continuar exercendo a profissão dita como a mais antiga do mundo (DONEL, 2011; SILVA, 2008).

Agora que temos clareza que trabalhar como meretriz é reconhecidamente um prestação de serviço, o presente artigo irá trazer o perfil dessas mulheres. Sobre o prisma do primeiro motivo escolhido. Temos: moças caucasianas, entre 18 e 26 anos de idade, filhas de pais de classe trabalhadora e mães geralmente domésticas. Algumas possuem ensino médio completo, outras chegaram até a ingressar no ensino superior, mas acabaram abandonando por não conseguirem manter não só as mensalidades das faculdades particulares, como também toda a logística que envolve cursar o nível superior, como adquirir apostilas, livros, transporte, comida, pacote de dados de internet, entre outros custos adicionais. Esses dois principais motivos levaram a maioria das entrevistadas, que cursavam o nível superior, a abandonar as faculdades, entre o segundo e o quarto semestre.

Além da questão dos custos para manter uma faculdade particular, ainda há a questão de horário de atendimento dos clientes, que não segue o horário comercial. Isto é, como a maioria das entrevistadas trabalham usando aplicativos e sites de encontros especializados, a todo o momento elas são acionadas e precisavam sair no meio das aulas para não perderem clientes que, muitas vezes, só podem ser atendidos naquele determinado horário.

Como algumas das famílias das profissionais não sabem do ofício, ao tentar manter a discrição, as profissionais optam por atender os clientes no horário que supostamente deveriam estar em sala de aula, culminando, quase sempre, em perda do semestre letivo da faculdade, reprovações por faltas, não cumprimento das atividades acadêmicas propostas, entre outros motivos diversos. Algumas profissionais do sexo relataram que sentiam vergonha de seus professores e colegas de classe, uma vez que tinham de atender chamadas telefônicas durante as aulas e combinar preços e tipos de programas dentro da sala de aula.

Como o controle de circulação para maiores de 18 anos em sala de aula é menos complexo, algumas meninas precisavam conversar abertamente com seus professores sobre seus trabalhos, numa tentativa de justificar suas ausências constantes, ou saídas inesperadas no meio das aulas, na tentativa de achar alternativas para não reprovar e continuar os estudos.

Foram também relatados episódios de bullying que as profissionais sofrem por parte dos colegas que sabem o motivo de suas saídas corriqueiras. Seja pela rotina, pela grande rotatividade de carros que param para buscar e deixar essas moças dentro de um curto espaço de tempo, pelos vários atendimentos por telefone, ou pelo tempo quase fechado, de 1 hora entre a saída e o retorno delas para a sala de aula.

Alguns relatos narrados apenas como bullying se misturavam e se destacavam por se configurarem como assédio sexual. Estes aconteciam por parte dos funcionários da escola, como porteiros, serventes, secretários, colegas de classe e professores. Algumas foram chantageadas por esses homens e ameaçadas de terem suas vidas expostas as suas famílias e amigos, casos elas se negassem a prestar favores sexuais a eles. Agravando ainda mais a situação de vergonha e sentimento de impotência, o que as leva de garotas de programa à vítimas, em minutos.

\section{RESULTADOS E DISCUSSÕES}


Ires, de 18 anos de idade, relata que muitos sites escondem a presença do rufião. Agenciadores que teclam com os clientes, marcam os encontros, acertam os valores dos programas e o tipo de programa que o cliente deseja. Sites como FatalModel, Skokka, NorteSexy, Paradise Girl, SexBooking, entre outros, que são muito difundidos na internet e entre as garotas de programa. Logo depois de ver o portfólio da mulher no site, o cliente pode entrar em contato diretamente com a garota de programa escolhida, por meio de aplicativos de mensagem instantânea ou por telefone, para fechar o programa. Ires fez o seguinte relato:

Sabe Augusto, eu comecei a fazer programas quando eu tinha 15 anos. Eu tinha umas
colegas da minha sala que faziam programa e me colocaram nessa barca. Eu tentei me
cadastrar em 03 sites desse ai de programa. Um dos sites pediu minha identidade e
como eu sou de menor acabou não rolando. Eles ainda me deram o maior mijada. Mas
dois sites, eu me dei bem pra caralho. Só falei que tenho 18 anos e pronto [...]. Como
moro com a minha mãe e padrasto, eu não posso sair certos horários. Eu vivo
recebendo mensagem 24 horas dos caras. As vezes, faço uns 03 programas da hora
que eu vou para a aula. Essa porra de Pandemia fudeu com a minha vida, agora só
consigo fazer 01 programa por dia. O babado ficou tão foda pra mim, que eu tive de
pagar para o moderador marcar os programas pra mim [...] parte da grana, eu banco o
meu namorado. Ele é um frango, ele tem 19 anos e é barbeiro. Ele é liso o coitado
(risadas). Ele nem desconfia que eu saio com caras e ainda uso o dinheiro para pagar
as coisas pra ele. Eu amo aquele frangote.

Tanto Ires quanto outras garotas que foram entrevistadas durante a pesquisa de campo, relatam que vivem relacionamentos amorosos, mas que seus companheiros desconhecem ou em alguns casos já as questionaram, mas não sabem que suas namoradas, companheiras e esposas trabalham no mercado da prestação de serviços sexuais. Muitas utilizam o dinheiro que ganham para ajudar os seus cônjuges com despesas do lar, no caso das mulheres casadas ou que vivem em regime de união estável, outras ajudam a custear os estudos, passeios, presentes e negócios de seus noivos ou namorados.

Já as mulheres mais jovens, que ainda estão sob o jugo dos pais, e não têm parceiros amorosos fixos, utilizam a maior parte do valor ganho nos programas para sustentar as "vaidades" e comprar bens de consumo que estão muito além das possibilidades de seus pais. Em entrevista com Lírio, de 19 anos de idade, ela revela que:

Eu não preciso fazer isso porque minha mãe e meu padrasto bancam os meus estudos e tudo mais. Meu pai paga pensão. Só que eu quero comprar as coisas que eles não podem me dá como esse Iphones aqui que eu uso, maquiagem, roupas de marca, bolsas caras e sapatos. Eu sou cara! (risadas). Eu não faço com qualquer um aí. Eu olho a lata do cara antes no Whats e peço até foto. Se eu não for com a cara do maluco, eu não saio. Sabe Augusto, eu amo é o dinheiro e não dou de graça ainda mais para pobre, feio e liso. Odeio homem liso. Tenho que aproveitar que tô nova e com tudo durinho (risadas). Depois quando tudo cair, eu quero ter grana para fazer minhas cirurgias plásticas e levantar tudo (risadas). Quem gosta de homem é veado, mulher gosta é de grana! (risadas). Mulher é artigo de luxo. Então, sexo é só para quem tem dinheiro para pagar.

A partir não só do relato de Lírio, e mais de inúmeras meretrizes, se fez necessário a confecção da tabela abaixo, para entendermos quanto custa em média um programa com essas mulheres. A tabela abaixo foi confeccionada utilizando os mais diversos sites especializados em mediar encontros sexuais, e da mesma forma, tabular também os valores que as garotas de programa afirmavam que cobravam durante as entrevistas. Thompson (2002, p. 14) explica a importância do uso da estatística somada à História oral, para melhor entender como os grupos de pessoas apresentam comportamentos diferenciados dos seus pares: 
A partir das estatísticas pode-se estimar o número das famílias de Bangladesh, se homens e mulheres têm trabalho remunerado, e mesmo sua renda e pobreza relativa. Mas, sem relatos em profundidade, é impossível compreender porque eles, mais do que outros vizinhos e parentes, foram para a Inglaterra; como experimentaram a mudança entre duas culturas totalmente diferentes; o que significa ser uma mulher de Bangladesh coberta pelo véu nas ruas de um país ocidental altamente sexualizado; quais são suas esperanças e aspirações para o futuro. A história oral pode nos contar isso, não só sobre esses grupos, como também sobre uma interminável gama de grupos migrantes, no Brasil ou em qualquer lugar do mundo (THOMPSON, 2002, p. 14-15).

Assim, os dados da tabela nos subsidiarão na busca por resposta acerca da dinâmica que atrela maiores ganhos ou menores ganhos às características étnicas. Assim como subsidiar a melhor compreensão do segundo motivo que nos levou a escolha do público-alvo da presente pesquisa.

Tabela 1 - Relação características físicas x idade x tipo de programa x valor.

\begin{tabular}{|c|c|c|c|}
\hline Características Físicas & Idade & Tipo de Programa & Valor Médio \\
\hline \multirow{4}{*}{$\begin{array}{l}\text { Branca, cabelos loiros ou ruivos, } \\
\text { estatura alta ou mediana, olhos } \\
\text { azuis ou verdes. }\end{array}$} & $18-23$ & $\begin{array}{c}\text { Padrão } \\
\text { Completo }\end{array}$ & $\begin{array}{l}\mathrm{R} \$ 400-600 \\
\mathrm{R} \$ 600-800\end{array}$ \\
\hline & $24-29$ & $\begin{array}{c}\text { Padrão } \\
\text { Completo }\end{array}$ & $\begin{array}{l}\mathrm{R} \$ 250-350 \\
\mathrm{R} \$ 350-450\end{array}$ \\
\hline & $30-35$ & $\begin{array}{c}\text { Padrão } \\
\text { Completo }\end{array}$ & $\begin{array}{l}\mathrm{R} \$ 200-250 \\
\mathrm{R} \$ 250-300\end{array}$ \\
\hline & $35-40$ & $\begin{array}{c}\text { Padrão } \\
\text { Completo }\end{array}$ & $\begin{array}{l}\mathrm{R} \$ 150-180 \\
\mathrm{R} \$ 180-220\end{array}$ \\
\hline \multirow{4}{*}{$\begin{array}{l}\text { Branca, cabelos pretos baixa ou } \\
\text { mediana, olhos castanhos ou } \\
\text { pretos }\end{array}$} & $18-23$ & $\begin{array}{c}\text { Padrão } \\
\text { Completo }\end{array}$ & $\begin{array}{l}R \$ 300-400 \\
R \$ 350-500\end{array}$ \\
\hline & $24-29$ & $\begin{array}{c}\text { Padrão } \\
\text { Completo }\end{array}$ & $\begin{array}{l}\mathrm{R} \$ 200-250 \\
\mathrm{R} \$ 250-300\end{array}$ \\
\hline & $30-35$ & $\begin{array}{c}\text { Padrão } \\
\text { Completo }\end{array}$ & $\begin{array}{l}\mathrm{R} \$ 130-180 \\
\mathrm{R} \$ 150-200\end{array}$ \\
\hline & $35-40$ & $\begin{array}{c}\text { Padrão } \\
\text { Completo }\end{array}$ & $\begin{array}{c}\mathrm{R} \$ 100-120 \\
\mathrm{R} \$ 80-140\end{array}$ \\
\hline \multirow{4}{*}{$\begin{array}{l}\text { Parda, cabelos negros, estatura } \\
\text { variada, olhos negros, castanhos } \\
\text { ou verdes. }\end{array}$} & $18-23$ & $\begin{array}{c}\text { Padrão } \\
\text { Completo }\end{array}$ & $\begin{array}{l}\mathrm{R} \$ 150-200 \\
\mathrm{R} \$ 200-250\end{array}$ \\
\hline & $24-29$ & $\begin{array}{c}\text { Padrão } \\
\text { Completo }\end{array}$ & $\begin{array}{l}\mathrm{R} \$ 120-150 \\
\mathrm{R} \$ 150-200\end{array}$ \\
\hline & $30-35$ & $\begin{array}{c}\text { Padrão } \\
\text { Completo }\end{array}$ & $\begin{array}{l}\mathrm{R} \$ 100-120 \\
\mathrm{R} \$ 120-150\end{array}$ \\
\hline & $35-40$ & Padrão & $\mathrm{R} \$ 80-90$ \\
\hline
\end{tabular}


Completo

$\begin{array}{lcc}\text { 18-23 } & \text { Padrão } & \mathrm{R} \$ 120-150 \\ & \text { Completo } & \mathrm{R} \$ 150-180 \\ 24-29 & \text { Padrão } & \mathrm{R} \$ 100-120 \\ & \text { Completo } & \mathrm{R} \$ 120-150 \\ 30-35 & \text { Padrão } & \mathrm{R} \$ 80-100 \\ & \text { Completo } & \mathrm{R} \$ 90-110 \\ 35-40 & \text { Padrão } & \mathrm{R} \$ 50-60 \\ & \text { Completo } & \mathrm{R} \$ 60-80\end{array}$

$\mathrm{R} \$ 90-110$

$\mathrm{R} \$ 120-150$
$\mathrm{R} \$ 150-180$

(1)

\begin{abstract}
Negra, cabelos negros, estatura variada, olhos negros ou castanhos.
\end{abstract}


O terceiro item mais importante na hora de determinar o valor do cachê é o tipo de programa que a profissional do sexo oferece. Há mulheres que dividem os programas em sexo simples, ou seja, vagina, com camisinha; outras colocam um valor maior para o sexo simples sem camisinha; há diferenças maiores ainda quando se tem o completo, ou seja, oral, vaginal e anal, com ou sem camisinha; por fim, tem os valores maiores ainda quando são convidadas para realizarem sexo em grupo, com ou sem camisinhas; por fim, o valor maior a ser cobrado pelas mulheres são aqueles serviços sexuais realizados em eventos fechados em que geralmente a meretriz é paga por diária, não por horas. Além de clientes que pagam cachês muito mais elevados para a operária do sexo se submeter a relações fora da rotina sexual regular. Contudo, em regras gerais, os programas são basicamente divididos em completo e básico.

A partir da compreensão do valor dos programas, que foi detalhado na tabela acima, podemos começar a dissertar o segundo motivo para a escolhas desse grupo de 05 mulheres que compõem o presente artigo. A questão latente da não aceitação de suas aparências físicas, e os bullying que elas sofreram ao longo da infância e adolescência. Os relatos coletados durantes as entrevistas revelaram que existe uma questão mais profunda ligando a forma com que essas mulheres usam a prostituição.

Thompson (2002, p. 16) explica que como historiadores orais, jamais deveríamos ficar satisfeitos com abordagens aleatórias para escolher aqueles que irão ouvir, uma vez que isso enfraquece seriamente as conclusões que podem ser tiradas de suas entrevistas. Em todo projeto se faz necessário dar a correta atenção à formulação de estratégias apropriadas de amostragem. Existem, obviamente, diversos tipos diferentes de amostragens possíveis. Para o pesquisador criar uma amostra plenamente representativa, esse deve retirar uma sub-amostra de um survey existente, ou produzir uma nova amostra aleatória ou por cota, local ou nacional.

Segundo Souza (2007), cada mulher apresenta motivos específicos para justificar sua prática, como estar desempregada, almejar sair da casa dos pais, necessitar de manter terceiros, como filhos e pais, e até mesmo buscar por um status social. Para Molina e Kodato (2005), a crise econômica e social pelas quais passam a maioria das mulheres é uma das principais causas de entrada na prostituição, e nesse espaço encontram uma possibilidade real de geração de renda suficiente e rápida.

No entanto, em nossa pesquisa, a prostituição está intimamente e assombrosamente ligada aos ganhos exponencialmente rápidos, para tratamentos de beleza e cirurgias que possam trazer satisfação pessoal, e a auto afirmação dentro de padrões estéticos de beleza, outrora inalcançáveis, vista a realidade humilde dessas mulheres. A questão do uso do corpo para obter vantagens financeiras e revertê-las em procedimentos estéticos e/ou plásticas nos saltou os olhos durante as entrevistas com as operárias do sexo, entre os 18 e 21 anos, entre essas, não foram feitos relatos a respeito de desejos e planos de futuro envolvendo carreira profissional fora da prostituição, casamentos e filhos. Correia e Holanda (2012, p. 430) afirmam que para continuar no mercado, as mulheres precisam se diferenciar em seus atributos físicos e sociais. Sendo assim, o culto à beleza e a preocupação com os modismos fazem parte do cotidiano dessas mulheres. Logo, numa sociedade em que "ser bonita" e "estar bem vestida" é quase um sinônimo de realização pessoal, sucesso e felicidade, fugir a esses padrões pode ser visto como uma ameaça às possibilidades de trabalho.

Vale ressaltar que durante outra pesquisa de campo, realizada em 2018, que gerou um artigo intitulado "A prostituição em grandes projetos na Amazônia: o impacto do grande capital nos fluxos de mão de obra na UHE Belo Monte" realizada na cidade de Altamira, (FIGUEIREDO, 2018) observou diversos relatos de mulheres que afirmavam quererem deixar a prostituição o mais breve possível. Mulheres que queriam um emprego mais ortodoxo, que buscavam um companheiro para casar-se, desejavam constituir família ou abrir um negócio próprio. A comércio do sexo era tido por essas mulheres, entrevistadas em 2017, como um fim 
que justificava os meios. Na presente pesquisa, notamos uma mudança de paradigmas por parte das operárias do sexo.

Observamos nos relatos da presente pesquisa, uma preocupação maior com a questão estética; motivações mais voltadas para a aquisição de bens materiais, viagens e entretenimento. Mulheres que usam os valores obtidos com a venda de serviços sexuais na prostituição para pagarem implantes de silicone nos seios e nos glúteos, lipoaspirações, abdominoplastias, bichectomias, metoplastias, blefaroplastia, rinoplastias, aplicações de toxina botulínica, tratamentos dentários com implantes e facetas, entre outros procedimentos estéticos. Bruns e Guimarões (2010) explicam que:

Por outro lado, a prostituição pode ser uma maneira de ganhar muito dinheiro com rapidez, mais do que se ganharia em qualquer outra profissão, fazendo com que a mulher possa participar mais ativamente da sociedade de consumo. Nesse caso, a questão financeira não seria fator relevante apenas para as prostitutas de classe social baixa, pois existem profissionais do sexo da classe média e alta que buscam melhores condições financeiras, e pela prostituição poderiam se dar ao luxo de possuir uma vida mais confortável, que não apenas permitisse consumir-lhes, roupas de grife e perfumes caros, mas também ter sonhos e desejos de estar inseridas num mundo mágico, criado pela mídia e apresentado como lugar onde se é feliz (BRUNS e GUIMARÃES, 2010).

Os procedimentos estéticos e cirúrgicos que têm como propósito melhorar a aparência para elevar ainda mais as possibilidades de ganhos com os programas, somados a uma melhora da autoestima dessas mulheres. Uma vez que a clientela paga valores mais substanciais para mulheres que tenham um padrão de beleza mais difundido pela internet, redes sociais, mídias televisivas, pela moda, pelas novelas e produções cinematográficas.

São mulheres, em sua maioria loiras, com corpos fisicamente esculturais, com cabelos longos, seios e glúteos fartos, rosto fino e delicado, dentes perfeitos e principalmente uma aparência jovial. O padrão de beleza europeu e norte americano com pitadas tupiniquins no tocante aos glúteos.

Em entrevista com Violeta, de 21 anos de idade, a jovem revelou que desde criança é insatisfeita com o formato de seu nariz, essa insatisfação começou na infância e se acentuou na adolescência, com o bullying que sofria na escola e em sua vizinhança. $O$ bullying continuou acontecendo durante boa parte de sua adolescência. Ela, por outro lado, também passou a não aceitar o tamanho dos seios. Violeta, que é de família de baixa renda, entrou na prostituição por intermédio de uma amiga de sala de aula. A moça relata que viu na prostituição a chance de juntar dinheiro e mudar tudo aquilo que a incomodava durantes anos de sua vida, sobre essa situação Violeta diz:

Eu fui zoada muito tempo na rua de casa, na escola, pela geralzona. Eu chorava quase todo o dia porque o meu apelido era nariz de bolota, porquinha, narizinho, nariz de palhaça, bozo e o caralho a quatro. Ai depois aqueles filhos da puta começaram a me chamar de peito pequeno, de machinho, de sem peito e de despeitada. Eu via as molecas da minha rua e da minha sala com peitões, e eu era a fudida sem peito. Um dia, eu vi a Ana, uma doida da minha sala saindo num carrão de um velho. Depois de mais de uma hora ela voltou para a escola. Eu chamei ela e falei: Qual é a do velho? Ele te banca? Quanto tú cobra? Foi quando ela me deu a letras na real e me colocou dentro. Ele foi a minha cafetina. Arrumava as barcas pra mim, e eu tinha que dá uma parte pra ela. Ela foi a primeira mulher que eu curti. $\mathrm{O}$ velho queria curtir com duas meninas ao mesmo tempo. Então, Ana me chamou para a barca com ela. Depois que curti com a Ana, eu comecei a sair também com mulher. Ai, depois que eu já sabia fazer os paranauês, eu mandei ela tomar no cú [...]. Paguei 13 mil conto pelos peitos e depois mais 10 mil conto para fazer o nariz. Levei 03 anos dando muito a pepeca e engolindo muita porra para levantar essa mixaria toda. Agora, eu vou colocar bunda e depois perna. Vou dominar o mundo! Ninguém me segura mais! (risadas). 
Durante as entrevistas, foi observado que muitas jovens acabam entrando no mundo da prostituição levadas por colegas de classe, primas e algumas por parentes mais velhas, como tias e cunhadas. Existe dentro dessa dinâmica da prostituição, muitas vezes perversa, um toque de curiosidade por parte dessas jovens, visando a questão financeira. Com esse objetivo financeiro em mente é fácil cair nas mãos de rufiões experientes em convencer mulheres a ingressarem de corpo e alma na carreira de prostituta.

Além, é claro, do cliente, que busca sempre a satisfação de seus desejos e impulsos sexuais, com a iniciante na carreira, a qualquer custo, e faz com que um único cliente sempre disposto a pagar pelo serviço seja visto iniciante como um dinheiro "fácil, seguro, rentável e sedutor" para muitas mulheres a prostituição é um mundo mágico de ganhos "fáceis". Bauman (1998) afirma que este mundo mágico é um mundo criado, pois estamos diante de um mercado voltado ao consumidor, como afirma vigorosamente, com a intenção de manter uma procura infinitamente insatisfeita, ou seja, há sempre uma busca por novas experiências e sensações que irão aparecer, acreditando-se estar em busca da felicidade.

Clientes que pagam para realizarem todos os seus desejos, não se importando com quem eles estão usando para isso, entre esses relatos destacamos: clientes que pediam para que elas fizessem as suas necessidades fisiológicas em cima deles ou vice-versa; homens que pediam para que essas mulheres se vestissem como crianças; pedidos para que a mulher os chamassem de pai, mãe, tio e tia; pedidos para que as profissionais fingissem que estavam dormindo para que eles fingissem que estavam as estuprando; clientes que queriam introduzir nas partes íntimas das garotas de programa os mais diversos objetos, tais como garrafas pet de 2 litros de refrigerante; clientes que pediam para amarrar ou serem amarrados e açoitados; clientes que levam os seus animais de estimação e pedem para as prostitutas manterem relação sexual com eles e os seus animais.

São tão variados os relatos que essas mulheres fizeram, de situações que passaram a sentir repulsa por esses clientes. Muitas se recusaram a satisfazer tais fetiches, que como elas bem classificaram, são fetiches doentios. Entretanto, algumas delas acabaram se submetendo pelo auto valor financeiro que esses clientes oferecem. Para Bauman (1998), a enorme sedução do mercado acarreta uma grande divisão de águas: de um lado os que podem arcar com esses desejos e do outro aqueles que não podem, caracterizando, assim, uma marca de sucesso e fracasso.

Magnólia, de 26 anos de idade, detalhou em sua entrevista que aceitou fingir que estava dormindo para que dois clientes, que pagaram cerca de um mil reais, para que ela fingisse um suposto "falso" estupro. De acordo com o relato de Magnólia, essa já havia feito outros programas com dois homens ao mesmo tempo. Logo, achava que a questão do "falso" estupro era apenas um fetiche, e que ela teria total controle da situação. Ao chegar no sítio de um dos clientes, na cidade de Tucuruí, eles a amarraram a cama, a amordaçaram e fizeram todo o tipo de atrocidades durante quase uma hora.

Ela não os denunciou a polícia por medo, pois os clientes além de terem um alto poder financeiro, tinham também a conversa no aplicativo de mensagem instantânea, onde eles falavam do fetiche, e ela aceitou participar pela quantia oferecida. Magnólia relatou, durante a sua entrevista, que jamais se recuperou do ocorrido, e que tem súbitos ataques de pânico durante atos sexuais corriqueiros, seja com seu namorado ou com outros clientes.

Isto posto, quem são esses clientes que geralmente procuram a companhia de profissionais do sexo por meio digital? De acordo com os dados levantados durante as entrevistas, os clientes são, na maioria, homens, entre 28 e 50 anos de idade, casados, de classe média e alta, de variadas profissões como comerciantes, bancários, médicos, advogados, engenheiros, dentistas, Web designers, professores, entre outras. Homens que buscam viver 
uma relação fora do casamento, com mulheres mais jovens que suas esposas, ou que buscam realizar as suas fantasias sexuais que não conseguem realizar com seus cônjuges.

Russo (2007) explica que a procura por prostitutas é motivada pela busca de um tipo específico de mulher, de prazer ou de fantasia sexual, por isso, que não se trata de um serviço prestado por qualquer mulher ou homem, mas por uma profissional específica, que é a meretriz, uma vez que essa está inserida em um contexto bastante particular, que proporciona sensações próprias, e um leque de possibilidades e experiências bastante específicas.

Alguns clientes, aparentemente, pelos relatos, apresentam desvios de ordem sexual e acabam encontrando nas profissionais do sexo a oportunidade de fazerem inversões de papeis sem serem julgados, o que muito provavelmente ocorreria caso tentassem fazer o mesmo em suas casas, com suas esposas. Outros apenas por pura compulsão sexual e apelo carnal. Existe uma parcela menor de mulheres que são casadas, têm filhos e empregos estáveis, mas que escondem de seus maridos e da sociedade, como um todo, a sua homossexualidade.

Ires relatou que muitas clientes casadas que, habitualmente saiam com ela, a convidavam para fazer programas em suas casas com os seus maridos. Essas clientes usavam o aniversário de seus maridos como pretexto para levá-la para as suas casas e a oferecer como presente surpresa para os seus cônjuges. Ires narra, que praticamente todas as vezes, que foi "dada" como presente de aniversário para os maridos de suas clientes, as esposas participavam do ato sexual juntamente com os maridos. Ires detalhou um desses encontros a três:

Ela é advogada e tem uns 42 anos eu acho, montada na grana é casada e tem até filho. Ela me disse que sempre gostou de curtir com mulher, mas a família dela não aceitaria, e eles são da igreja e tal. Ai ela curte com as "prima" aqui como eu, ela curte com puta e não é de hoje essa parada não mano. Ela mora numa casa do caralho. Eu fui lá um dia porque ela me pagou para curtir com o marido dela, Porra, era para o pateta me comer, mas quem mais me comeu foi ela. Se ele não se tocou que ela é sapato naquele dia, ele deve ser cego. Ganhei quinhentão para curtir com os dois. Muita mais que ela me paga pra curti comigo aquela mão de vaca do caralho. Tu acredita que ela paga $\mathrm{R} \$ 150$ para sair comigo.

Todavia, existe o cliente que tem necessidade afetiva. Durante uma entrevista com Lótus, ela mostrou fotos no aplicativo de mensagens que utiliza para manter contato com os seus clientes. Falou dos mais assíduos e mais antigos homens que costuma atender. O relato que ela fez de um dos clientes acabou chamando a atenção, não por ser um relato sexual na sua essência, mas por ser um relato que demonstrou um enorme afeto pelo cliente e vice-versa.

Esse aqui é o Felipe, ele tem 38 anos, e é um dos meus melhores clientes. Ele é sempre muito gentil e amoroso. Muitas vezes, ele traz presentinhos como bombons, flores, perfumes e já até me deu um brinco de ouro. Ele é funcionário público da Polícia Federal, ele é casado e tem duas filhas lindas. A esposa dele é médica e trabalha na polícia federal também. Eu sempre o vejo as quarta-feira por causa da mulher dele que tá sempre ocupada nos dias de quarta. As vezes, ele marca e vamos para um motel, outras vezes para um hotel, e passamos duas horas só conversando mesmo. Eu nem tiro a roupa. Ele só quer conversar mesmo. Fala dos problemas do trabalho, dos problemas da casa dele e das filhas. Eu adoro a companhia dele. Mas não curto muito transar com ele não. Ele é meio travado. Começamos a sair tem quase dois anos. Ele diz que sou a namoradinha dele das quartas. Acho que ele é carente muito carente. Ele precisa muito de alguém para conversar, e ele achou em mim uma pessoa pra ouvir ele (risadas). Recebo sempre R $\$ 100$ transando ou não transado com ele. É um dinheiro muito fácil.

Questões de cunho afetivo estão muito presentes dentro das relações comerciais. No artigo intitulado "Dinheiro, afeto, sexualidade: A relação de prostitutas com seus clientes", Burbulhan, Bruns e Guimarães (2012, p. 673) relatam que as profissionais do sexo, do estudo 
realizados por elas, corroboraram que os clientes não as procuram exclusivamente para práticas sexuais, muitas vezes desejam apenas conversar e desabafar as preocupações e problemas relacionados à família, ao trabalho e à própria masculinidade. Burbulhan, Bruns e Guimarães explicam, ainda, que nas falas das participantes de sua pesquisa foi possível perceber a grande gama de motivações que levam os clientes a buscar as profissionais do sexo. Percebemos que ambos se utilizam do dinheiro para suprir suas necessidades. Os clientes pagando e elas recebendo.

Burbulhan, Bruns e Guimarães finalizando dizendo que assim, nessa díade, ambos estão à procura de suprir suas carências, sejam elas econômicas, emocionais, psicológicas ou, ainda, biológicas. Para o cliente, o dinheiro paga, além da satisfação de determinadas carências, pela manutenção de uma sexualidade masculina herdada do modelo patriarcal de ser homem.

\section{CONSIDERAÇÕES FINAIS}

O objetivo deste artigo foi responder a alguns questionamentos sobre a prestação de serviços sexuais, entre eles: mesmo sendo considerada uma das profissões mais antigas do mundo, ainda existe a dúvida: a prostituição é ou não uma profissão? E se realmente a prostituição é uma profissão reconhecidamente legal, dentro do sistema jurídico brasileiro.

Foram abordados, ao longo do artigo, questões de cunho metodológico, em especial, ao que concerne aos desafios enfrentados para a execução da pesquisa em tempos de pandemia mundial; visto que adentrar ao mundo da prostituição, apresenta riscos para os pesquisados. Além de obter o consentimento de alguns cafetões, cafetinas e das próprias meretrizes para realizar as entrevistas.

O presente trabalho também buscou fazer uma relação entre características físicas, faixa etária e tipo de programa para determinar os valores. Foi confeccionada uma tabela, a qual detalhou e demonstrou que mulheres caucasianas, com idade entre 18 e 21 anos, que oferecem serviços sexuais diversos, ganham os maiores cachês se comparadas com mulheres negras, com maior idade, mesmo essas prestando os mesmos leques de serviços que as mulheres caucasianas.

Foi traçado um breve perfil dos clientes que procuram esse tipo de serviço. Assim como foram detalhados relatos de algumas relações vividas entre clientes e operárias do sexo, por meio de narrativas coletadas ao longo das entrevistas. Constatamos, por meio dos relatos, que nem sempre o cliente busca uma relação sexual. Existem fatores que envolvem o emocional e o psicológico, os quais entram no jogo da prestação de serviços sexuais.

As narrativas utilizadas nesse trabalho são utilizadas não somente para ilustrar as fundamentações teórica. Os questionários abriram caminho para conversas mais abertas e espontâneas, que serviram para dar voz as profissionais do sexo, durante o processo de escrita desse artigo. Voz que, majoritariamente, vivem silenciadas à sombra da sociedade.

Com esse trabalho, foi possível concluir que, majoritariamente, o que ainda leva mulheres a escolherem ser profissionais do sexo é o dinheiro. São mulheres que buscam uma vida financeiramente melhor, e como a maioria tem pouca instrução, acabam optando por essa atividade. Além de uma parcela significativa das jovens que optam pelo meretrício para ganhar de forma mais rápida, grandes somas, e usá-las em cirurgias plásticas ou/e procedimentos estéticos que visam corrigir, por meio destes, "imperfeições" físicas. Além de tentarem amenizar dores psicológicas, advindas de processos de bullying sofridos na infância/adolescência, ou mesmo de forças externas que as levam a buscar um padrão de beleza "Hollywoodiano", amplamente difundido pelas mídias sociais, televisivas e cinematográficas. 


\section{REFERÊNCIAS}

ALBERTI, Verena. Fontes Orais. História dentro da História. In: PINSKY, Carla Bassanezi (org.). Fontes Orais. São Paulo: Contexto, 2005, p. 155-202.

AQUINO, Priscila de Souza; NICOLAU, Ana Izabel Oliveira; PINHEIRO, Ana Karina Bezerra. Caracterização social de prostitutas frente à visão integral da saúde. remE - Rev. Min. Enferm.;12(1): 11-16, jan./mar., 2008.

BANUTH, Raquel de Freitas; SANTOS, Manoel Antônio dos. Discriminação e Resistência de uma Prostituta. Psicologia: Ciência e Profissão Jul/Set. 2016 v. 36 n³, 763-776, 2016. DOI: $10.1590 / 1982-3703002862015$.

BAUMAN, Zygmunt O mal-estar da pós-modernidade. Rio de Janeiro: Jorge Zahar, 1998.

BRAH, Avtar. Diferença, diversidade, diferenciação. Cadernos Pagu, (26), 329-376, 2006. doi:10.1590/S0104-83332006000100014

BRASIL. Ministério do Trabalho. CBO - Classificação Brasileira de Ocupações. Disponível em: http://www.mtecbo.gov.br/cbosite/pages/saibaMais.jsf, 2002. Acesso em: 03 dez. 2020.

BRUNS, Maria Alves de Toledo. A prostituição e sua nova embalagem. Conversando sobre sexualidade. São Paulo: Ômega, 2001.

BRUNS, Maria Alves de Toledo \& GUIMARÃES, Roberto Mendes. Garota de programa: uma nova embalagem para o mesmo produto. Campinas: Átomo, 2010.

BRUNS, Maria Alves de Toledo; GOMES JUNIOR, Osvanir Pereira Prostituição: o discurso de quem se vende e o silêncio de seu comprador. Jornal Brasileiro de doenças sexualmente transmissíveis. v.8, nº4: 4-13. Niterói, dez. 1996.

CORRÊA, Willian Henrique. \& Holanda, Adriano Furtado. Prostituição e sentido de vida. Psico-USF, Bragança Paulista, v. 17, n. 3, p. 427-435, set./dez, 2012

DAVID, Priscila. História Oral: Metodologia do Diálogo. São Paulo, Unesp, v. 9, n. 1, p. 157-170, janeiro-junho, ISSN - 1808-1967, 2013.

DONEL, Pedro. A regularização da prostituição. Jus Brasil, 2011. Disponível em: https://espaco-vital.jusbrasil.com.br/noticias/2629880/a-regularizacao-da-prostituicao. Acesso em: 03 dez. 2020.

FRANÇA, Genival Veloso. Prostituição: um enfoque políticosocial. Femina, Rio de Janeiro, v. 22, n. 2, 2012, p. 145-148. Disponível em: http://www.derechoycambiosocial.com /revista029/Prostitui\%C3\%A7\%C3\%A3o.pdf. Acesso em: 03 dez. 2020.

GUIMARÃES NETO, Regina Beatriz. Violência e Trabalho na Amazônia: narrativa historiográfica. Revista Territórios \& Fronteiras, Cuiabá, vol. 7, n. 1, abril, 2014, p.27-46.

MAYORGA, Cláudia. Cruzando fronteiras: prostituição e imigração. Cadernos Pagu, (37), 2011, 323-355. doi:10.1590/S0104-83332011000200014. 
MOLINA, Ana Maria Ricci, \& Kodato, Sérgio. Trajetória de vida e representações sociais acerca da prostituição juvenil segundo suas participantes. Temas em Psicologia, 13(1), 2005, 09-17.

PISCITELLI, Adriana. Prostituição e Trabalho. In: Transformando as relações trabalho e cidadania: Produção, Reprodução e Sexualidade. São Paulo, 2007.

RODRIGUES, Marlene Teixeira. A prostituição no Brasil contemporâneo: um trabalho como outro qualquer? Rev. Katál. Florianópolis v. 12 n. 1 p. 68-76 jan./jun. 2009

SILVA, Mario Bezerra da. Profissionais do sexo e o Ministério do Trabalho. In: Âmbito Jurídico, Rio Grande, XI, n. 59, nov, 2008. Disponível em: http://www.ambitojuridico.com.br/site/index.php?n_link=revista_artigos_leitura\&artigo_id=5233. Acesso em: 02 dez. 2020.

SOUZA, Fabiana. Rodrigues. Saberes da vida na noite: percepções de mulheres que prestam serviços sexuais sobre o educar-se nas relações com seus clientes. 2007 Dissertação (Mestrado em 2007). Programa de Pós-Graduação em Educação, Universidade Federal de São Carlos, São Carlos, São Paulo, Brasil, 2007.

PASINI, Elisiane. Sexo para quase todos: a prostituição feminina na Vila Mimosa. Cad. Pagu, 25, 2005, 185-216. Disponível em:

http://www.scielo.br/scielo.php?script=sci_arttext\&pid=S0 104-

$83332005000200008 \& \operatorname{lng}=$ pt\&nrm=iso. Acesso em: 03 dez. 2020.

PORTELLI, Alessandro. Sonhos Ucrônicos. Memórias e possíveis mundos dos trabalhadores. Projeto História, São Paulo, n.10, 1993, p. 41-58.

RODRIGUES, Fernanda. (2003). Ação Social na Área da Exclusão Social. Universidade Aberta. Lisboa.

RUSSO, Gláucia. No labirinto da prostituição: o dinheiro e seus aspectos simbólicos. Cad. CRH, 20, 2007, 497-514. Disponível em:

http://www.scielo.br/scielo.php?script=sci_arttext\&pid =S0103-

$49792007000300009 \& \operatorname{lng}=e n \& n r m=i s s o$. Acesso em: 03 dez. 2020.

SARAIVA, Luís Junior Costa. O renascer de vénus: Prostituição, trabalho e saúde em tempos de SIDA. ICS: Universidade de Lisboa, 2009.

THOMPSON, Paul. A voz do passado: História oral. Rio de Janeiro, Paz e Terra, 1992.

THOMPSON, Paul. História oral e contempo raneidade. História oral, 5, 2002, p. 9-28. 